\title{
Review
}

Digestion

Published online: November 12, 2013

DOI: $\underline{10.1159 / 000353603}$

\section{Artificial Nutrition and Intestinal Mucosal Barrier Functionality}

\author{
Chrysostomos D. Anastasilakis $^{a}$ Orestis loannidis ${ }^{c}$ Athina I. Gkiomisi ${ }^{b}$ \\ Dimitrios Botsios ${ }^{\mathrm{C}}$ \\ Departments of a Pharmacology and b Obstetrics and Gynaecology, 424 General Military Hospital, and \\ 'Fourth Surgical Department, Medical School, Aristotle University, Thessaloniki, Greece
}

\section{Key Words}

Artificial nutrition - Mucosal barrier - Mucosal immunity .

Bacterial translocation - Neuropeptides · Bombesin ·

Neurotensin · Arginine · Glutamine

\begin{abstract}
The gastrointestinal tract has a major role in digestion and absorption of nutrients while playing a leading role in defense of the body. It forms a shield against the invasion of various microorganisms or their products (e.g. antigens, toxins) and therefore it is important to establish its integrity and functionality. That depends on the route of administration and the composition of the artificial nutrition. This study concentrates on the influences of different kinds of artificial nutrition in the functionality of the intestinal mucosal barriers. It seems that full macromolecular solutions of enteral nutrition ensure an adequate mucous immune response, while a lack of nutritional stimulus in the lumen leads rapidly to a dysfunction of gastric-associated lymphatic tissue and mucosal immune system. This dysfunction renders the patients susceptible to infections in distant organs, hospital pneumonia, and multiorgan failure of non-infectious etiology. In patients with indication of total parenteral nutrition administration, addition of bombesin or glutamine preserves mucosal immune response and may limit the adverse effects.

(c) 2013 S. Karger AG, Basel
\end{abstract}

\section{Introduction}

Total parenteral nutrition (TPN) has significantly improved the survival of patients with loss of functional or anatomical integrity of the gastrointestinal tract (GI). On the other hand, food passage through the GI ensures operational efficiency of an important immune defense mechanism, the lymphatic tissue of the intestinal mucosa [mucosal-associated lymphoid tissue (MALT)]. Clinical studies of multitrauma patients have shown that TPN application, as opposed to enteral nutrition (EN), was accompanied by significantly higher rates of hospitalacquired pneumonia, septic intra-abdominal collections and possibly multiple organ failure syndrome [1-4].

\section{Anatomy and Physiology of Intestinal Mucosal Barrier}

Intestinal epithelium has a complex role as it allows absorption and excretion of substances necessary for body homeostasis and at the same time it acts as a barrier to various pathogens or their products. The anatomical and physiological integrity of the intestinal mucosal barrier (IMB) is therefore essential. The intestinal mucosa covers the intestinal lumen in all its length and consists of three layers, which from the outside to the inside are (i)

\section{KARGER}

E-Mail karger@karger.com www.karger.com/dig
(C) 2013 S. Karger AG, Basel

0012-2823/13/0883-0193\$38.00/0
Orestis Ioannidis

Alexandrou Mihailidi 13

GR-54640 Thessaloniki (Greece)

E-Mail telonakos@hotmail.com 


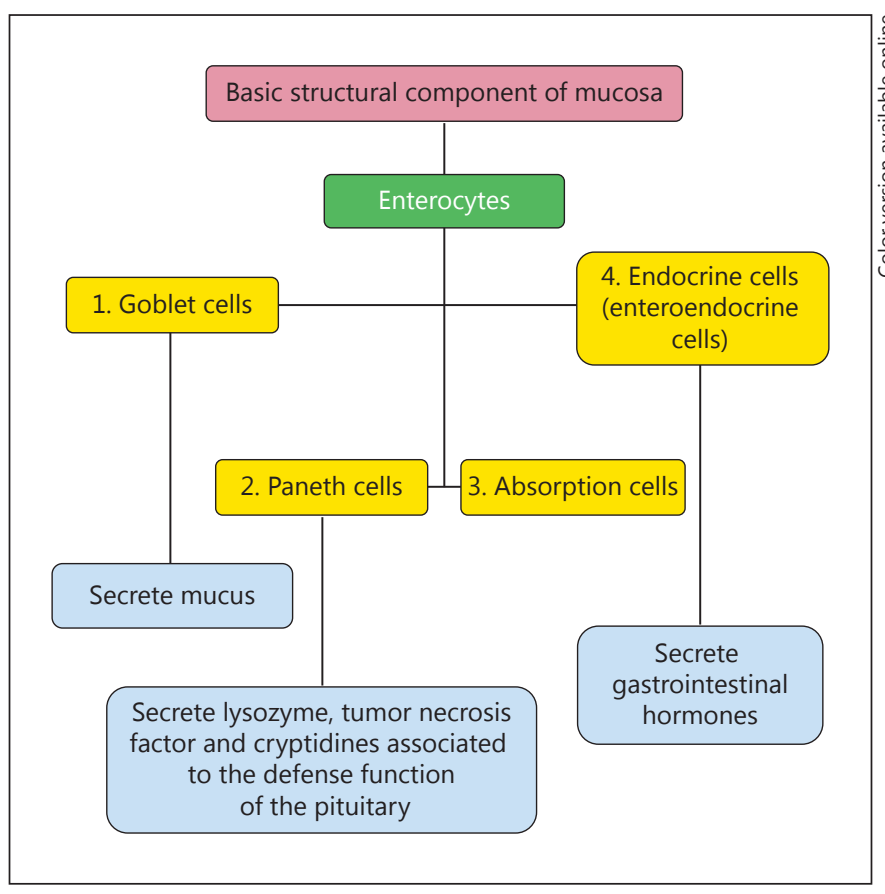

Fig. 1. Cells of the intestinal mucosa and their function.

the basement membrane (lamina propria); (ii) the mucosal muscular layer, and (iii) the epithelium covering the intestinal villus and crypts $[5,6]$. The main groups of basic structural component of mucosa are presented in detail in figure 1 [5] and immunological and non-immunological defense mechanisms of IMB $[5,6]$ in figure 2 .

\section{Deprivation of Enteral Nutrition}

TPN solutions are extremely hyperosmolar and are infused into a large central vein, so that the high blood flow will dilute rapidly the hypertonic solution. Caution is needed given that central venous catheters are often the source of septic complications. In addition, patients receiving TPN are at increased risk for intraperitoneal septic complications and hospital pneumonia, compared to patients under EN or with no nutritional support [7].

In one of the first studies dealing with these complications, Moore and Jones [1] randomized trauma patients in those receiving EN and those receiving intravenous (IV) hypertonic glucose solutions. The EN group had showed significantly fewer septic complications and abdominal septic abscesses. In another study, in patients with similar injury severity, those who received EN exhib- ited significantly lower rates of septic complications and hospital pneumonia and a lower trend for intraperitoneal abscesses compared to patients receiving TPN [2]. Kudsk et al. [3] randomized 98 patients with extremely severe abdominal trauma and high severity index trauma in two groups: enteral and iso-protein-isothermal parenteral nutrition (PN). Once more, hospital pneumonia, intraabdominal abscesses, septic complications of the IV catheter, and septic episodes per patient were more frequent in the group of PN. Interestingly, the greatest differences between the two groups were observed in the patients with the more severe injuries. Despite the findings of all the above studies, the hypothesis that TPN has an unfavorable effect on gut immunity, although attractive, is yet unproven. There is no direct evidence in human models that TPN promotes bacterial overgrowth, impairs neutrophil functions, inhibits blood's bactericidal effect, or causes villous atrophy. Thus TPN may be more expensive than EN, but it does not seem to be less safe [8]. It is probably the lack of EN rather than reduced GI immunity or the absolute caloric intake that is responsible for many of the adverse effects of TPN such as induction of villus atrophy, epithelial cell apoptosis, and increasing of mucosal permeability [9].

A 6-day treatment of catabolic rats with $25 \% \mathrm{EN}$ and $75 \%$ PN has no appreciable benefits in small intestine cellularity and immunity [10]. On the other hand, EN should be preferred over TPN in the nutritional support of patients with acute pancreatitis, because it is cheaper and is associated with suppression of the immune inflammatory response, has fewer septic complications, a reduced need for surgical management of pancreatitis complications and a reduced hospitalization period, but does not seem to affect mortality or the rate of non-septic complications [11].

Specific dietary factors that are added to solutions of artificial EN appear to provide additional protection. Moore et al. [4] managed to reduce the rate of intra-abdominal abscesses and multiple organ dysfunction syndrome (MODS) in trauma patients using an immunostimulative solution of EN enriched with glutamine (GLN), n-3 fatty acids and nucleotides. Similarly, highrisk patients [12] fed a special immunostimulative solution had a significantly lower rate of intra-abdominal abscesses compared with patients fed an equal caloric and protein value standard EN solution, and even lower than patients without nutritional support. Several factors have been proposed as responsible for septic complications after TPN administration. One hypothesis attributes these complications in bacterial translocation (BT) from the in- 


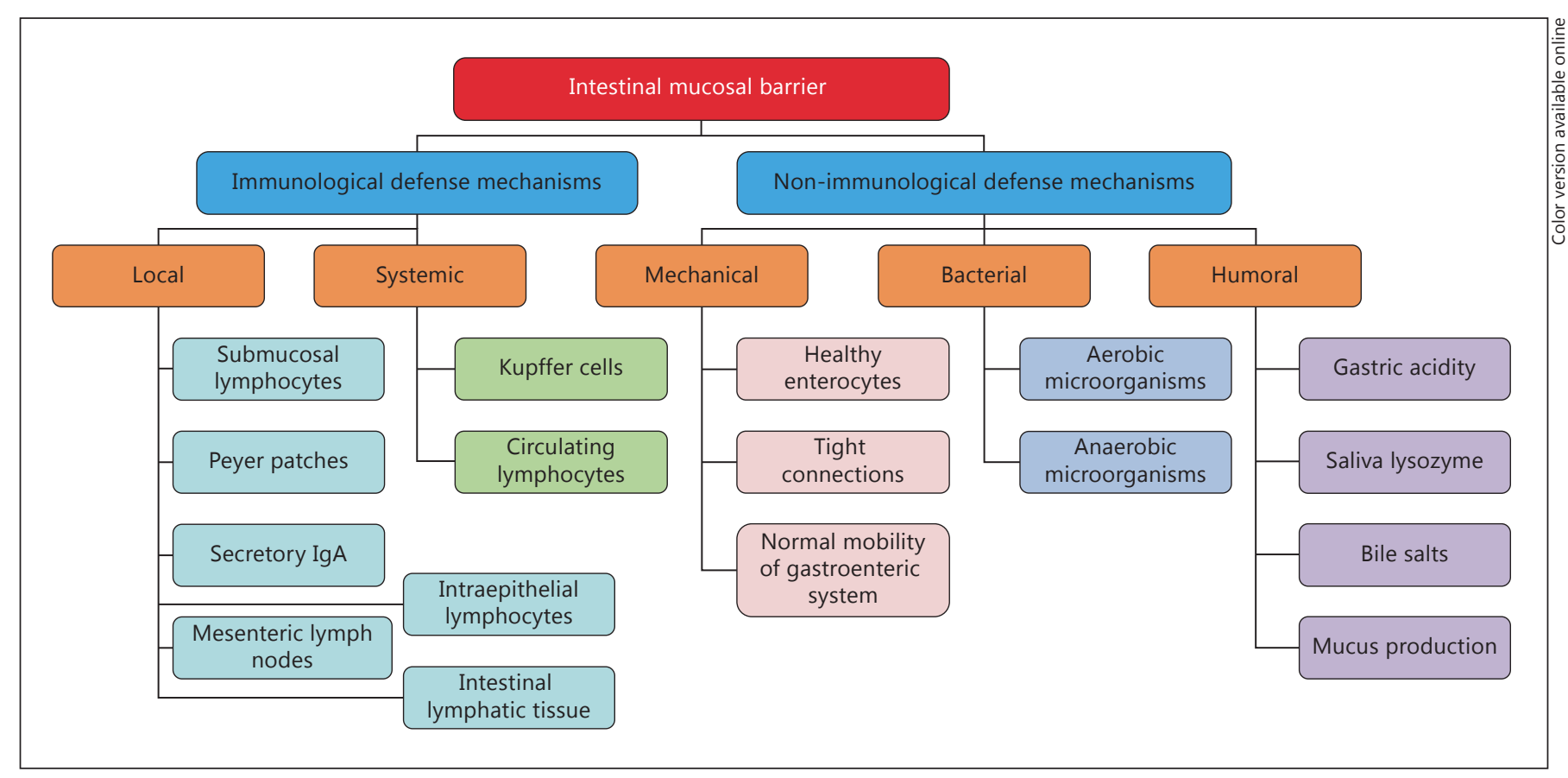

Fig. 2. IMB defense mechanism.

testinal lumen in remote locations via the mesenteric lymph vessels and systemic circulation. It has been shown that lack of food in the intestinal tract disrupts the functional integrity of the IMB, allowing BT [13]. A significant intestinal mucosal defense factor, the intestinal alkaline phosphatase, has the ability to detoxify lipopolysaccharides and prevent bacterial invasion across the IMB, and its expression and function are lost during starvation while maintained by EN [13].

\section{Bacterial Translocation}

$\mathrm{BT}$ is the phenomenon during which living microorganisms or their products or both cross the intestinal barrier and enter the systemic circulation. After crossing the barrier, these elements initially reach the mesenteric lymph nodes (MLNs) and then, using the liver or spleen as intermediate stations, enter the systemic circulation [14]. The presence of bacteria in numbers $>10^{12} / \mathrm{ml}$ on the $200-\mathrm{m}^{2}$ surface of the intestinal lumen and the fact that only one layer of epithelial cells, the intestinal barrier, separates this population from the sterile environment of the inner organs, raised scientific interest and led to studies aiming to clarify how bacteria could pass through the barrier [15].
An experiment in dog models showed that bacteria and toxins can cross the intestinal barrier and enter the systemic circulation [16]. Later it was proposed that the intestinal lumen could serve as a reservoir of bacteria that could penetrate the intestinal barrier and cause sepsis. In intensive care units, the syndrome of systemic inflammatory response syndrome (SIRS) and MODS represent the most frequent cause of death, with the exception of brain damage or bleeding during the first $48 \mathrm{~h}$. In such cases, although in many patients the infection site is evident in others, no source of infection is found. The pathogenesis of this phenomenon remains unknown; however, several studies support the theory of BT. Bacteria can escape the IMB causing fatal syndromes [17] and BT has been linked to SIRS, acute respiratory distress syndrome and MODS [18]. Mucosal barrier permeability is increased in sepsis, trauma, burns and vascular or major abdominal surgery [19-22].

A small amount of low residual diet could prevent decreases in gut mucosal integrity in Donryu rats [23]. The integrity of mucosal barrier is critical for prevention of BT in acute pancreatitis. In this setting, adequate oxygen delivery and nutrient supplementation may be proven helpful [24].

A common feature of BT is the mechanism of ischemia-reperfusion. The hypoxia in the intestinal mucosa 
Fig. 3. Route of entrance of germs or toxins

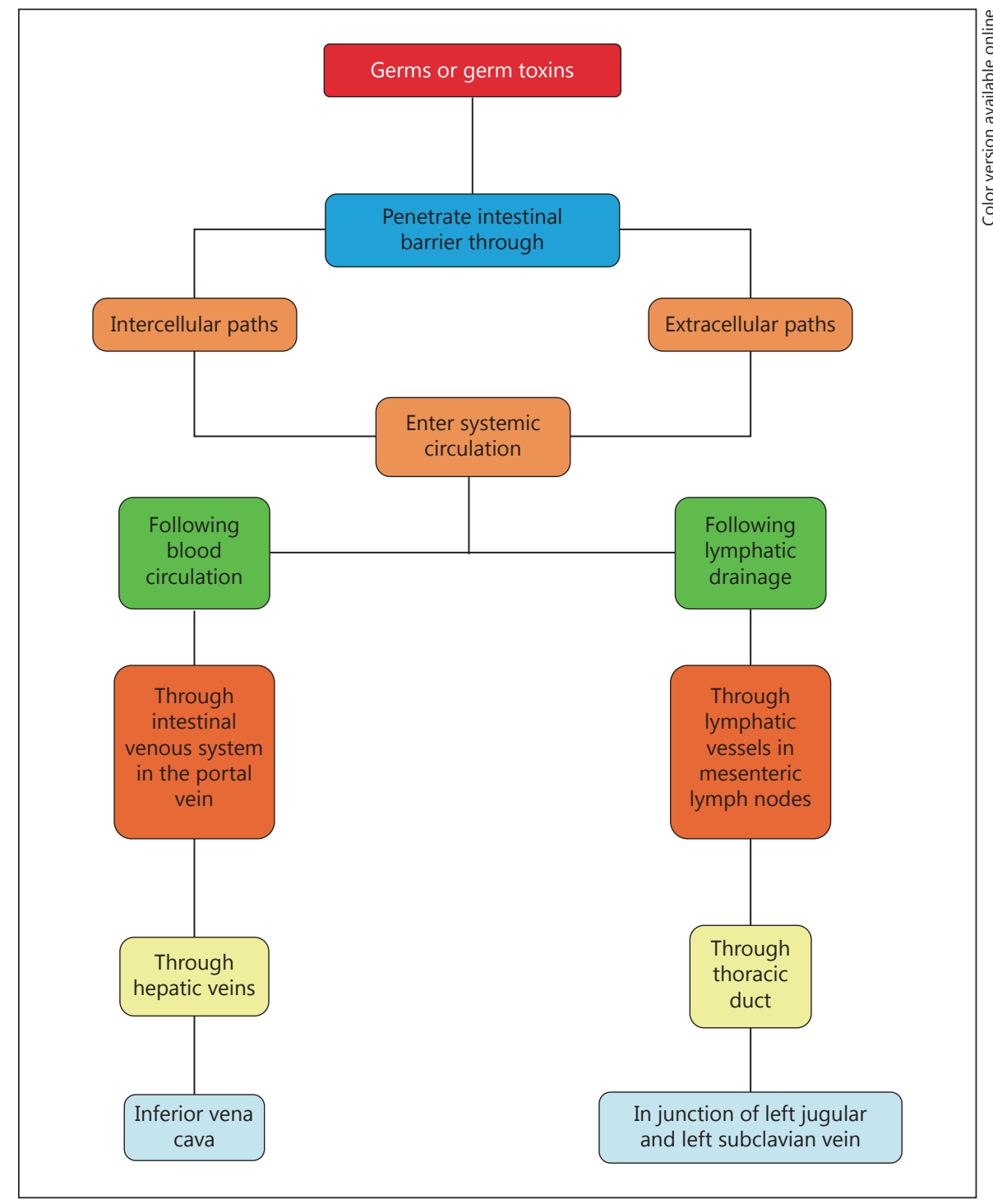
in the systemic circulation.

is often more pronounced than in other tissues because in case of shock the redistribution of blood to protect vital organs results in reduced blood flow in the intestine compared with other organs. The decreased blood flow in turn causes acidosis because of anaerobic metabolism and lactic acid production. The production of free oxygen radicals $\left(\mathrm{O}_{2}^{-}\right)$breaks down the cytoskeleton of the intestinal cells and increases their permeability. The free radicals may also affect the intestinal barrier through activation of the granulocytes [15]. Normally, bacteria that cross the intestinal barrier are destroyed by the phagocytes before entering the systemic circulation. Therefore, malfunction of the intestinal lymphatic tissue [gutassociated lymphoid tissue (GALT)] is a prerequisite for
BT [15]. Other factors that affect the integrity of the intestinal barrier include the overproduction of nitric oxide (NO) and interleukin (IL)-6, alcohol consumption, non-steroidal anti-inflammatory drugs, and common bacteria such as Escherichia coli and Klebsiella pneumoniae. Normal levels of NO have antibacterial properties, thus protecting the IMB. However, NO overproduction has the exact opposite effect, being toxic for the cells of the intestinal epithelium [15]. Thus, NO synthase is an important mediator of intestinal barrier dysfunction and administration of its inhibitor S-methylisothiourea is useful in the prevention of diet-induced barrier failure [25]. 
Fig. 4. Three-hit model of intestine involvement in the onset of systemic inflammatory response.

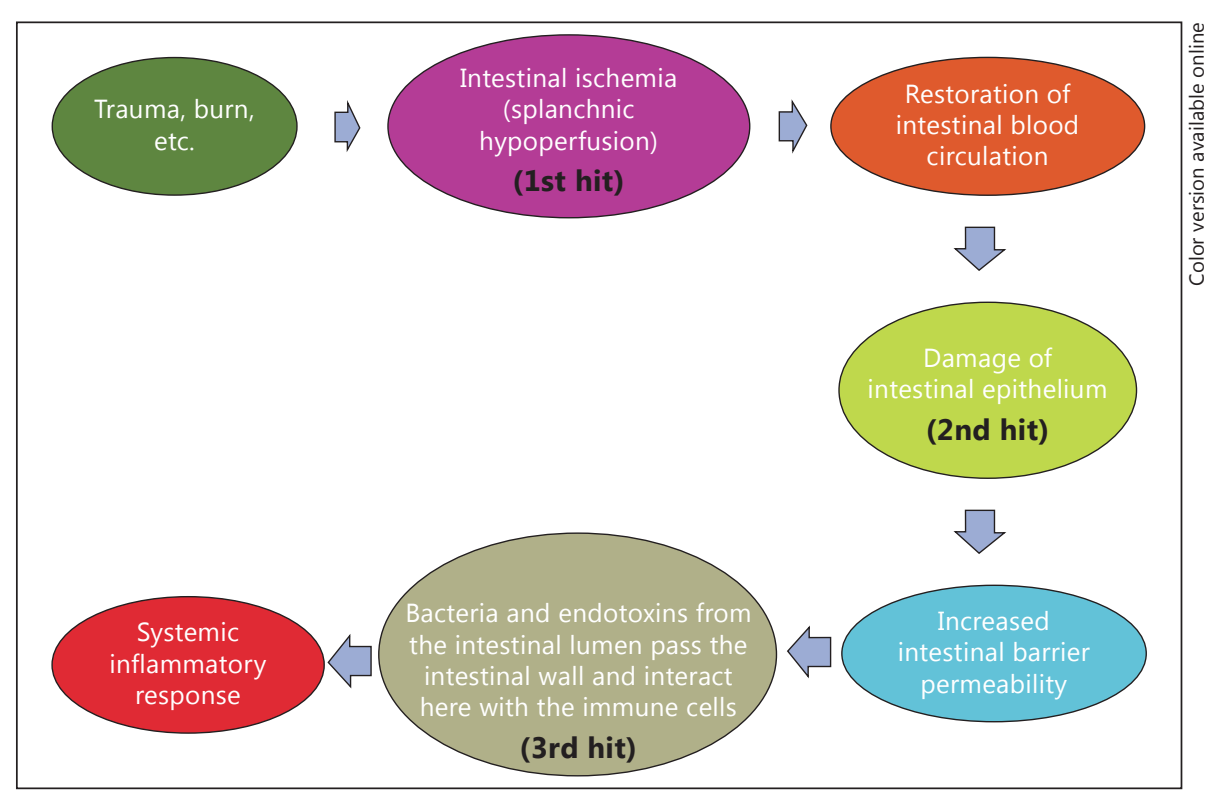

The bile salts are non-immunological protectors of the IMB. The bile salts interact with endotoxins in the intestinal lumen resulting in the formation of less permeable molecules. Reduced production of bile salts and the consequent disruption of normal flora could explain BT in case of obstructive jaundice, cirrhosis or hepatectomy [26-28]. Immunonutrition may protect the gut barrier function more effectively in rats with SIRS [29], can protect IMB in rats with operative stress, increase the expression of occludin, maintain the gut epithelial tight junction, and eliminate gut BT [30]. Also, it may contribute to the maintenance of IMB integrity. In dogs with severe acute pancreatitis, EN for 7 days significantly decreased the serum levels of amylase, aminotransferase and albu$\mathrm{min}$, the plasma endotoxin, and the incidence of BT, and alleviated inflammation in the pancreas and injury in the ileum [31].

Although simple calorie-protein starvation does not cause BT, addition of a non-enteral inflammatory factor dramatically increases the BT from the intestinal lumen to the MLNs, liver, spleen, and lungs. Despite these experimental data, a link between BT and MODS or nonenteral septic complications has not been established in humans [7]. Moreover, Moore et al. [32] found no BT in blood cultures from the portal vein of multitrauma patients during the immediate posttraumatic period. BT may take place by two routes: by blood circulation or by lymphatic drainage presented in detail in figure 3.
Several studies have attempted to clarify which of the two routes is the mainstream of BT in systemic circulation. Moore et al. [32] collected portal blood samples from 20 patients hospitalized in the intensive care unit after trauma surgery. During the initial surgery a catheter was placed in the inferior vena cava of these patients to draw blood at $6,12,24,48 \mathrm{~h}$ and 5 days postoperatively in order to grow cultures and measure endotoxin levels. Only $2 \%$ of the obtained cultures were positive and no correlation between the endotoxinemia and the subsequent development of SIRS/MODS was observed. These results contradicted the hypothesis that BT could cause SIRS and MODS and led to the investigation of alternative $\mathrm{BT}$ routes, mainly the lymphatic drainage. Animal studies have shown that MLNs are the first and often the only organ containing migrating microorganisms and that endotoxin levels were elevated in the major thoracic duct [33]. These observations led to the hypothesis that sepsis and organ failure could be caused by substances transferred from the intestine to the systemic circulation through the lymphatic system and not the bloodstream [33]. Deitch and co-workers [34] found that separation of the major thoracic duct from the systemic circulation may prevent the development of SIRS/ MODS in rats after trauma and that components of lymph and not of portal blood can stimulate the immune system. Since no bacteria were found in the cultures of MLNs and endotoxin levels were undetectable, a direct effect of bacteria or endotoxins to damage distant organs 
must be ruled out. These results were in accordance with a clinical trial investigating the lymph in patients hospitalized in intensive care units. In these patients, the lymph of the major thoracic duct was bacteria-free and very low endotoxin levels were detected. No correlation was found between patients with detectable endotoxin levels and those who developed MODS [35]. The intestine produces non-bacterial proinflammatory agents, which may enter the systemic circulation through the lymphatic drainage and cause systemic inflammatory response regardless of the presence of germs or endotoxins. Furthermore, bacteria and endotoxins may cross the intestinal barrier and be trapped in the intestinal wall or MLNs, where they stimulate the production of various cytokines by the lymphatic system contributing to the systemic inflammatory response. However, this 'local' BT presupposes the elimination of the intestinal barrier. The three-hit model of intestine involvement in the onset of systemic inflammatory response appears in figure 4. It has been suggested that intestinal permeability is markedly increased after burns and is positively correlated to the gut-derived endotoxinemia. Early enteral feeding in severely burned patients and in acute pancreatitis may decrease intestinal permeability, preserve the IMB and have a beneficial effect on the reduction of enterogenic infection [36, 37].

Given the conflicting results on the BT, an attempt to find an alternative mechanism to explain increased frequency of hospital pneumonia and intra-abdominal abscesses in patients not treated with EN was made based on the immune response of the intestinal mucosa.

\section{Mucosal Immunity}

Gut stimulation after feeding induces a generalized immune response in the human MALT through a mucosal immune network. Examples include the influence of enteral feeding in the neonatal development of the GALT, the presence of antigen-specific IgA-secreting cells and antigen-specific IgA in distant mucosal sites, such as the breast, after exposure to intestinal luminal antigen, and the isolation of IgA-producing cells from the peripheral blood [38]. The GALT is an essential compartment of the immune system. First of all, it has immunologic control over endogenous intestinal flora. Furthermore, GALT protects other distant organs such as lungs, nasopharynx, the mammary gland and the genitourinary system. The GALT is part of the larger MALT. The GI not only absorbs nutrients but also has an important immunologic role during health and critical illness. Under certain experimental and clinical conditions, stimulation by feeding of the intestine attenuates stress response, avoids mucosal atrophy and decreases permeability. A better understanding of intestine function and nutrient absorption has clinical implications in the treatment of critically ill patients [39]. After 5 days of treatment, a small amount of EN partially reverses $\mathrm{PN}$-induced GALT changes, suggesting beneficial but limited effects on gut mucosal immunity. More specifically, Peyer's patch (PP) lymphocyte numbers and small intestine IgA levels increased EN amount-dependently, whereas lamina propria lymphocyte numbers increased EN amount-independently [40]. Stimulation of GALT through EN is the key to the preservation of normal intestine bacterial flora and thus mucosal-derived immunity [41]. Lymphotoxin $\beta$-receptor (LT $\beta R$ ) expression is critical for GALT control mechanisms and intact mucosal immunity. Lack of enteral stimulation with PN reduces LT $\beta R$ expression, PP lymphocytes and intestinal IgA production. PN significantly reduced PP lymphocyte mass, human mucosal addressin cell adhesion molecule-1 (MAdCAM-1) mRNA, and intestinal IgA. As anticipated, LT $\beta$ R blockade in chow animals significantly decreases transcription of MAdCAM-1 gene and PP lymphocyte mass but not intestinal IgA, because chow feeding was maintained. Both LT $\beta$ R blockade and $\mathrm{PN}$ decreased IgA, but not significantly. The major mechanism for decreased GALT cells in absence of enteral stimulation is inadequate LT $\beta \mathrm{R}$ signaling $[42,43]$. Microfold cells ( $\mathrm{M}$ cells) are cells found in the follicleassociated epithelium of the PP. They transport organisms and particles from the gut lumen to immune cells across the epithelial barrier, and thus are important in stimulating mucosal immunity. $\mathrm{M}$ cells have the unique ability to take up lumen antigen of the small intestine via endocytosis or phagocytosis, and then deliver it via transcytosis to dendritic cells and lymphocytes which then enter as activated lymphocytes in PP, with the help of the MAdCAM-1 [44]. The sensitized lymphocytes are dispersed through the thoracic duct and systemic circulation in various submucosal positions, forming part of the centripetal part of the GALT. The basic membrane of the intestinal layers is one of the places that concentrates the activated $\mathrm{T}$ and $\mathrm{B}$ lymphocytes, where $\mathrm{B}$ lymphocytes become plasma cells and produce immunoglobulin A (IgA). After that, the polymerized IgA, being enriched with specific secretory factor epithelial cells, receptor of polymerized $\operatorname{IgA}$, is transported from the submucosal space within the intestinal lumen [44]. 
One of the main defenses of the GI is the synthesis and secretion of $\operatorname{IgA}$, as more than $70 \%$ of the cells that produce IgA are located in the intestine. Chow and complex enteral diets maintain a normal balance between IgAstimulating and IgA-inhibiting cytokines while preserving normal antibacterial and antiviral immunity. The IgA-stimulating cytokine IL-4 levels decrease significantly in mice receiving intragastric (IG) or IV nutrition along with IgA levels, whereas IL-10 decreases significantly only in mice receiving IV nutrition. These data are consistent with severely impaired mucosal immunity with IV nutrition and partial impairment with IG nutrition and provide a cytokine-mediated explanation for the reduction in diet-induced mucosal immunity $[45,46]$.

Exogenous treatment with combination of $\mathrm{PN}$ and IL-7 for 5 days reverses $\mathrm{PN}$-induced impairment of resistance to respiratory tract infections (bacterial pneumonia) associated with increased secretory IgA levels [47]. IL-7 treatment during PN appears to have beneficial effects on gut immunity, but other therapeutic methods are needed to restore secretory IgA levels. IL-7 dose-dependently restores PN-induced GALT cell loss but does not improve intestinal IgA levels [48].

IgA inhibits both the adherence of bacteria in the intestinal mucosa and their proliferation, while it inactivates the toxins produced by the bacteria and inhibits the absorption of antigens from the intestine $[5,6]$. PN impairs airway mucosal immunity by reduction in IgA available for transport rather than via a reduction in polymeric immunoglobulin receptor levels. In the small intestine, diminished polymeric immunoglobulin receptor is implicated in the deterioration of antibody-mediated mucosal immunity [49].

In animals, particularly mice, lack of intraluminal food stimulus results in a rapid, dramatic thickness of the basic membrane of the intestinal mucosa and reduction of total intraepithelial lymphocytes number in PP. In $72 \mathrm{~h}$ from interruption of the starvation, the B cells of PP and of basic membrane are reduced by $55-60 \%$ and $T$ cells by $40 \%$ [50]. At least partly responsible for this reduction is MAdCAM-1, as it directs the non-sensitized lymphocytes in the PP, and sensitized ones to the basic membrane. Both TPN and fasting downregulate MAdCAM-1 mRNA and protein levels in PP. The MAdCAM-1 changes are due to lack of enteral stimulation rather than toxic effects of PN. PN rapidly downregulates MAdCAM-1 gene expression [51]. Specifically after $8 \mathrm{~h}$ of PN, MAdCAM-1 mRNA levels decreased $20 \%$ while in 5 days the decrease in MAd-CAM-1 mRNA was $64 \%$ and in MAdCAM-1 protein levels $30 \%$. Fasting decreased MAdCAM-1
mRNA levels by $16 \%$ at 1 day and $30 \%$ at 2 days, compared with chow [51].

In animals, nutrition support with TPN for only a few hours leads to a significant decrease in MAdCAM-1 expression in $\mathrm{PP}$, while its levels rapidly return to normal after restoration of EN [52].

Furthermore, lack of intraluminal food stimulus causes imbalance in the cytokines that control lymphocyte maturation resulting in a decrease in CD4/CD8 ratio. CD4 lymphocytes produce IL-4 and IL-10, which stimulate IgA production [53]. Decreased enteral stimulation significantly alters key mucosal immune chemokine protein levels at multiple sites. PP chemokine (C-X-C motif) ligand 13 (CXCL13 protein) and small intestine chemokine (C-C motif) ligand 20 (CCL20) and chemokine (C-C motif) ligand 25 (CCL25 protein) levels significantly decreased, whereas chemokine (C-C motif) ligand 21 (CCL21 protein) increased significantly in the parenterally fed group. Chemokine (C-C motif) ligand 28 (CCL28) decreased significantly in the small intestine and lung of IV fed animals. mRNA levels changed in the opposite direction (compared with protein) for all chemokines except CCL28 [54].

In animals, TPN reduces IL- 4 and IL-10 levels in the intestine, while it increases interferon- $\gamma$ (IFN- $\gamma)$, which inhibits the production of IgA [45]. PN reduces in vivo IL-4 levels in PP (consistent with lower MAdCAM-1 expression) and IL-4 and IL-10 levels in gut homogenates compared with chow. Despite MAdCAM-1 blockade, enteral feeding preserved gut IL-4 levels and increased IL10 levels consistent with preserved IgA levels [55]. Enteral feeding affects MAdCAM-1 expression. Complete MAdCAM-1 blockade reduces GALT lymphocytes to PN levels, but the chow feeding stimulus preserves IgA and early antibacterial resistance, implying the existence of non-MAdCAM-1 mechanisms that preserve mucosal immunity [56].

TPN administration reduces without completely inhibiting IgA transportation across epithelium [57]. Of note, 3-day EN deprivation caused persistent reductions in IgA levels, not only in the intestinal lumen but also in the tracheobronchial complex [57]. A 5-day PN significantly reduces virus-specific IgA in nasotracheal washes and suppresses the selective transport index, suggesting impaired mucosal transport of polymeric (p)IgA. PN with specific antiviral pIgA in animals resulted in extinction of the virus from the airway and restoration of mucosal protection, suggesting sufficient residual transport may be the most important factor in maintaining respiratory tract IgA-mediated immunity [57]. The expression 
of a specific protein receptor that transports IgA is regulated by IFN- $\gamma$ and IL- 4 . TPN does not affect IFN- $\gamma$ but reduces IL-4 levels and therefore IgA receptor expression and subsequently the rate of transportation through the epithelium [58]. Lowering of intraluminal IgA as a consequence of enteral feeding deprivation is likely to be responsible for the higher frequency of hospital pneumonia in patients supported with PN. It was found that in animals immunized with Pseudomonas aeruginosa administration of a lethal dose of this germ 5 days after the initiation of TPN resulted in mortality of $70 \%$ higher than orally fed animals. The mortality rate of the latter was comparable to that of non-immunized animals, implying loss of specific antibacterial immunity [59]. In a similar study, after 5 days of TPN, influenza virus was administered intranasally in animals immunized against it. Two days later, nasal secretions of half the animals still contained the virus. On the contrary, the virus had disappeared completely in all animals fed with EN [60].

\section{Peritoneal Reaction}

In animals receiving TPN, the reaction of the peritoneum in intraperitoneal infectious causes may be manifested in various ways. In animals fed parenterally, intraperitoneal injection of bacteria caused significant reduction of the exudative cells in the peritoneal cavity compared with mice fed orally [61]. This reduction was attributed to weak peritoneal response to TNF- $\alpha$, increased proliferation of bacteria and intense response of vascular inflammatory cytokines. Ikeda et al. [62] studied the peritoneal reaction in a model of aseptic peritonitis, caused by intraperitoneal injection of $1 \%$ glycerol solution. Four hours after the injection, mice undergoing TPN had a significant reduction of all leukocyte subpopulations including neutrophils, lymphocytes and macrophages. Interestingly, the addition of $2 \%$ GLN in the PN solution restored the above abnormalities.

\section{Vascular Inflammatory Reaction}

Mucosal immune dysfunction caused by lack of enteral feeding is likely to be involved in the pathogenesis of MODS, due to severe, non-infectious systemic inflammatory response. Neutrophils and lymphocytes are known to have a central role in the pathogenesis of both non-specific immune inflammation response and multiple organ failure [63]. The vascular system of the GI sensitizes cells
Table 1. Potential mechanisms of action of the nutritional agents $[72,73]$

Dissociation of intraluminal antigens

Modulation of the bowel immune response

Improvement of the antioxidant status

Modified uptake of PUFAs (n-6/n-3 fatty acids)

Restoration of function of the IMB

Regulation of the intestinal microflora

Regulation of intestinal motility

Regulation of bile-pancreatic secretions

which, once activated, react to harmful stimuli, causing further tissue damage. Compared with EN regimens, TPN renders neutrophil more prone to activation, thus increasing their concentration in the GI. Intercellular adhesion molecule-1 (ICAM-1) is the endothelial homologous molecule of complex CD11/18 integrin. ICAM-1 promotes neutrophil settlement in the endothelium and their maturation rendering them capable of passing through the endothelial cells [64]. The IFN- $\gamma$ is a potent stimulator, while IL- 4 and IL-10 are potent inhibitors of ICAM-1 expression. Lack of EN does not affect IFN- $\gamma$ levels but significantly reduces IL-4 and IL-10 production [65]. Therefore, reduced expression of ICAM-1 in the endothelium of visceral vessels in patients receiving PN may be attributed to alterations in the production of these cytokines.

The adhesion of neutrophils to vascular endothelium is also influenced by $\mathrm{P}$ - and E-selectin. These adhesion molecules are expressed on the surface of endothelial cells and favor the flow of leukocytes along the endothelium of postcapillary veins. This flow leads to agglutination, through the action of the CD11/18 integrin and ICAM-1 complex. TPN increases the expression of P-selectin in the vascular endothelium of the GI and of E-selectin in the vessels of the lung [66]. The elevated levels of myeloperoxidase (MPO) in the GI of animals receiving TPN support the hypothesis that neutrophil concentration is associated with increased expression of adhesion molecules [67]. However, ICAM-1 and MPO levels were restored $4 \mathrm{~h}$ after oral refeeding. It seems that lack of EN causes a transient, non-specific inflammatory reaction which is mainly characterized by dysfunction of visceral vascular endothelium and which promotes neutrophil activation. This promotion of activation becomes evident when a second stimulus is applied in rats receiving TPN. Meyer and Kudsk [7] studied animals receiving TPN for 5 days and then subjected to a temporary complete obstruction of the upper mesenteric artery for $15 \mathrm{~min}$. They reported that 
$72 \mathrm{~h}$ after the restoration of blood supply the mortality was much higher in animals fed with TPN compared to those with oral feeding or enteral feeding or IG infusion of TPN solution before mesenteric artery obstruction (40 vs. $5-10 \%$, respectively). Furthermore, $3 \mathrm{~h}$ after the ischemic event, vascular permeability of the lung and liver were significantly higher in animals with TPN compared with those fed from the gut. Finally, while the expression of CD11a and CD11 b (neutrophil activation markers) before the ischemic event was similar in all groups of animals, $3 \mathrm{~h}$ later, CD11b expression was significantly increased only in animals fed with TPN, and the expression of CD18 increased only in the lungs of these animals, suggesting increased activation of myeloid cells.

\section{Composition of Enteral and Parenteral Nutrition Solutions}

Nutrient availability, enteric nervous system stimulation, and nutrient delivery affect mucosal immunity and may influence immunologic barriers and the inflammatory response [68]. There is evidence that $\mathrm{EN}$ and $\mathrm{PN}$, in diseases accompanied by mucosal barrier dysfunction, interact with the intestinal barrier and the immune system, by promoting wound healing and regulating T-cell function, enhancing the mucosal defense against $\mathrm{BT}$ and systemic inflammation [69]. There seems to be a diversification in the function of mucosal host defenses between $\mathrm{EN}$ and PN [70]. Therefore, EN, if tolerated, represents the feeding route of choice [71]. In table 1, we demonstrate potential mechanisms of action of the nutritional agents [72, 73].

Lung lymphotoxin $\beta$-receptor expression (LT $\beta \mathrm{R})$ is maintained with any diet in enteral feeding, whereas intestinal LT $\beta$ R levels are maintained only with complex enteral diets. In contrast, intravenous PN significantly reduced both intestinal and lung LT $\beta R$, while IG administration of the PN solution reduced only intestine LT $\beta$ R levels [74]. Thus, LT $\beta R$ preserves respiratory tract immunity when a non-complex, chemically defined enteral diet is administered, whereas intestinal immunity is compromised with the same diet [74]. EN support is preferred in surgical patients for preserving gut mucosal integrity [75]. Blood flow distribution depends on nutrient composition. Feeding with elemental solution compared with oral feeding partially suppresses the activity of intestinal lymphoid tissue but not in the magnitude that complete absence of the lumen dietary stimulus does [59]. On the other hand, there are clear differences when the same elemental solution is administered intravenously. Immunized animals exhibit $88 \%$ mortality from bacterial pneumonia when fed with TPN, 57\% when the same solution is given intra-abdominally and only $10 \%$ when fed exclusively with intestinal macromolecular solution of artificial feeding [59]. Prior antigenic immunization can protect against bacterial pneumonia. This protection is lost with intravenous TPN, partially preserved with a chemically defined enteral diet, and completely preserved with chow or complex enteral diets [59]. Various nutritional agents have been tested in inflammatory bowel diseases as alternative treatment, including antioxidants ( $\mathrm{GSH}$, vitamins $\mathrm{A}, \mathrm{C}$ and $\mathrm{E}$, selenium and zinc), lipids [ $\mathrm{n}-3$ polyunsaturated fatty acids (PUFAs) and short chain fatty acids], amino acids, prebiotics and probiotics, $\mathrm{N}$-acetyl-D-glucosamine (GlcNAc), and dietary particles [76]. Specific probiotic lactobacteria and plant fibers such as inulin may dramatically reduce the inflammation and the infiltration of organs such as the lungs by neutrophils, thereby controlling inflammation and eliminating unwanted pathogens, such as antibiotic-resistant microorganisms and Clostridium difficile [76]. Ischemia/reperfusion disrupted the structure of intestinal tight junctions and reduced occludin expression. n-3 PUFAs in male Sprague-Dawley rats, by gavage for 7 days before ischemia/reperfusion, indicates that $n-3$ PUFAs protect the intestinal barrier by elevating occluding and intracellular intestinal fatty acidbinding protein (I-FABP) in plasma while decreasing in cells, activating the peroxisome proliferator-activated receptor- $\gamma$ pathway, and then upregulating intestinal tight junction protein expression. A peroxisome proliferator-activated receptor- $\gamma$ agonist had the same effect as n-3 PUFAs [77]. Table 2 summarizes some interesting studies about the effects of $\mathrm{PN}$ and EN solutions to the immune system [78-83].

\section{Intestinal Nervous System}

As mentioned above, complete macromolecular solution of intestinal artificial nutrition, mimicking normal oral feeding, ensures functional integrity of the intestinal immune system compared with elemental solutions. The combination of all nutrients is considered to have an overall stimulatory effect in the lymphatic tissue of the intestine and is exerted through neurotransmitters and peptide transmitters. The interactions of lumen dietary stimuli with the lymphoid tissue and intestinal nervous system have been documented [84]. Within the intestinal 
Table 2. Effects of diet composition in the intestine and immune system

\begin{tabular}{|c|c|c|}
\hline Ref. & Composition and route of EN/PN solutions & Effect of EN/PN solutions \\
\hline 7 & $\begin{array}{l}\text { IG administration of elemental solution in animals after } \\
15 \text { and } 30 \text { min of acute visceral ischemia }\end{array}$ & $\begin{array}{l}\text { Provides the same survival rate with normal oral feeding at } 15 \mathrm{~min} \\
\text { but a lower rate at } 30 \mathrm{~min}\end{array}$ \\
\hline 49 & IG administration of elemental solution & $\begin{array}{l}\text { Reduces lymphocyte mass in PP, basic membrane and other } \\
\text { intraepithelial positions, reduces intraluminal IgA, IL-4, but not } \\
\text { IL-10 }\end{array}$ \\
\hline 78 & Immune-enhancing enteral diets & $\begin{array}{l}\text { Increases blood flow to the ileum and stimulates enteral mucosal } \\
\text { immunity }\end{array}$ \\
\hline 79 & IG administration of elemental solution & $\begin{array}{l}\text { Reduces expression of ICAM-1 in epithelial cells of the intestinal } \\
\text { mucosa but lesser than TPN }\end{array}$ \\
\hline 82 & PN with butyrate for 5 days & $\begin{array}{l}\text { Restores PP lymphocyte numbers, intestinal and bronchoalveolar } \\
\text { IgA levels, small intestine morphology, villous height and crypt } \\
\text { depth compared to PN }\end{array}$ \\
\hline 83 & $\begin{array}{l}\text { Wistar rats with dextran sodium sulfate ulcerative colitis, } \\
\text { administration of high levels of n-3 PUFAs for } 8 \text { days } \\
\text { once a day }\end{array}$ & $\begin{array}{l}\text { Increases neutrophil infiltration as depicted by myelohyperoxidase } \\
\text { activity, increases hematocrit and hemoglobin and shows a trend } \\
\text { towards histopathological and clinical improvement }\end{array}$ \\
\hline
\end{tabular}

wall there is a dense nerve plexus and neuropeptides, released from this dense neural network, regulate the bowel's movement, secretory function, development as well as mucosal defense mechanisms.

The neuropeptide that regulates gastrin secretion is produced by the intestinal nervous system. Exogenous administration of bombesin (BBS), an analogue of this peptide isolated from frogs, restores the TPN-induced intestinal lymphatic system atrophy and respiratory defense mechanism dysfunction [85].

Long-term PN reduces the size of ileal PP, the number of microspheres that was taken up into the follicle-associated epithelium of lymphoid nodules, and the number of intraepithelial lymphocytes within the follicle-associated epithelium near the perifollicular crypts of PP and the area of PP surface occupied by $\mathrm{M}$ cells. These effects were strikingly milder with BBS administration, although no structural changes of the M cells in PP were observed. Thus, BBS seems to regulate the formation and particle transport by $M$ cells, through stimulation of lymphoid cells in PP epithelium near perifollicular crypts, where M cells and other constituents of lymphoid follicle epithe- lium are generated, and thereby preserving mucosal immunity. In conclusion, $\mathrm{BBS}$ prevents the $\mathrm{PN}$-induced atrophy of GALT, the reduction of M-cell numbers, and the decrease in particle transport by $\mathrm{M}$ cells during long-term PN [86]. Although MAdCAM-1 is considered the gateway molecule for cell entry into mucosal immunity, this does not seem to be the mechanism for mucosal immunity preservation in non-enterally fed mice receiving BBS or GLN. MAdCAM-1 expression in non-PP sites is not significantly increased from TPN levels either with BBS or GLN supplementation [87]. BBS reverses the effects of TPN on intestinal and respiratory tract IgA levels and most of the effects on gut cytokines. Lamina propria cytokine mRNA levels reflect total gut cytokine concentration. TPN-fed mice have significantly lower respiratory tract IgA levels than chow- or TPN+BBS-fed mice. TPN+BBS does not increase intestinal IL-10 or its mRNA levels in lamina propria, while intestinal IL-4 levels and lamina propria mRNA expression are similar to those of chow-fed mice [88].

BBS action is applied either directly to the GALT or through stimulation of gastrin and/or cholecystokinin 
Table 3. Role of BBS in the intestine and immune system

\begin{tabular}{|c|c|c|}
\hline Ref. & Experiment & Effect of BBS \\
\hline 85 & TPN with BBS & $\begin{array}{l}\text { Prevents lymphocyte reduction in PP, in basic membrane and other intraepithelial sites, maintains } \\
\text { the CD4/CD8 ratio of basic membrane, restores intraluminal IgA levels }\end{array}$ \\
\hline 90 & BBS administration & Restores the TPN-induced dysfunction of the IgA-dependent respiratory defense mechanism \\
\hline 91 & BBS administration & $\begin{array}{l}\text { Reduces the high mortality rate due to pneumonia (Pseudomonas) at similar levels to normally fed } \\
\text { animals }\end{array}$ \\
\hline
\end{tabular}

Table 4. Role of NT in the intestine and immune system

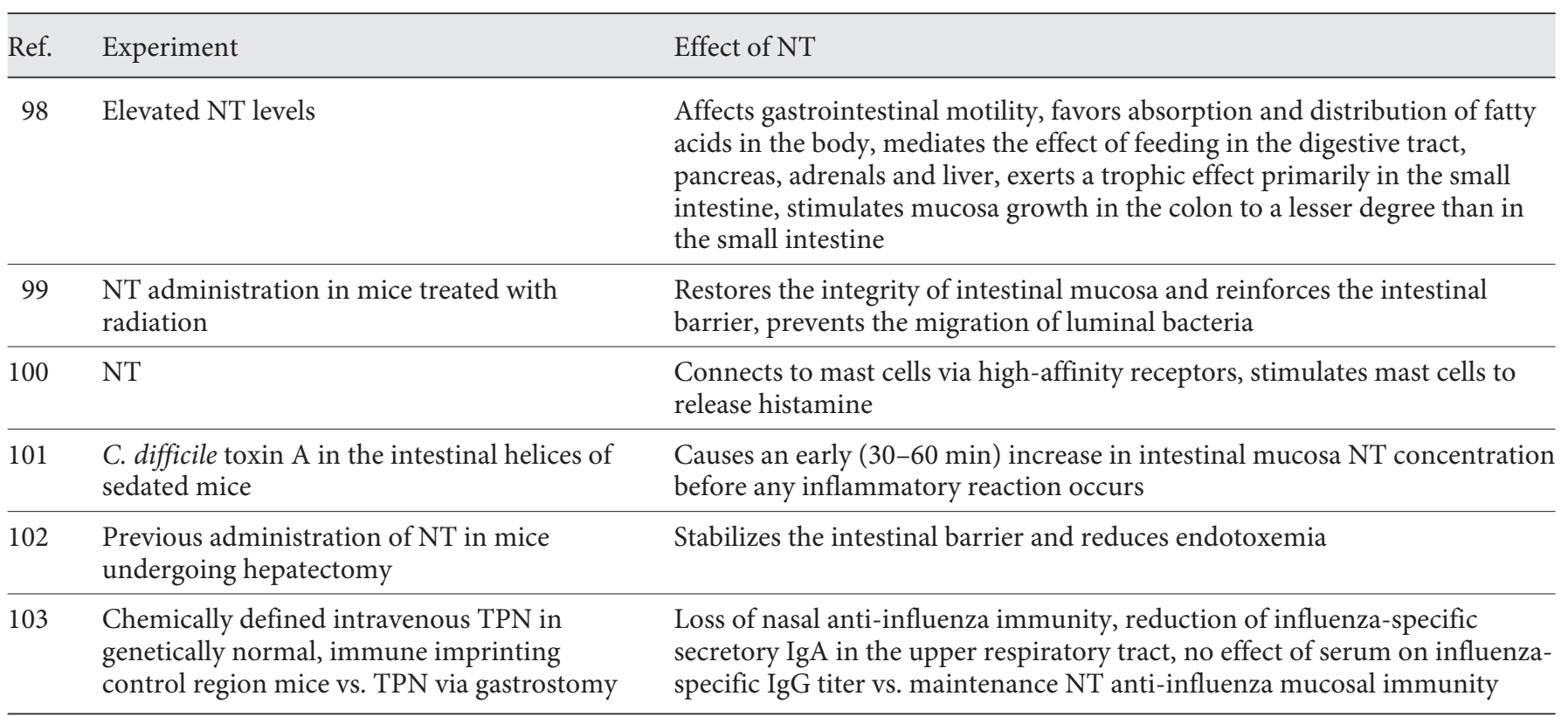

(CCK) and/or neurotensin (NT) secretion. Although PN decreases mucosal immunity outside the gut, specific nutrients, surrogates to EN, like GLN and neuropeptides such as gastrin-releasing peptide and CCK, may prevent some of the immune defects associated with PN. These factors may represent promising adjuncts to parenteral feeding, capable of maintaining immune function in patients unable to be fed via the GI [89]. Table 3 highlights the roles of BBS in the immune system [90-92].

In experimental models, simultaneous administration of either gastrin or CCK or NT with TPN had a different and in each case beneficial effect on GALT [93]. NT is a 13 -amino-acid peptide stored in granules in NT-containing cells ( $\mathrm{N}$-cells) which are scattered in the epithelial lay- ers of the jejunum and ileum [94]. All three neuropeptides retained the overall lymphocyte mass of PP, but each one acted in a different point. Gastrin and CCK acted mainly in the PP of the jejunum, while NT acted mainly in the ileum. All these neuropeptides also contributed to the restoration of intraluminal IgA levels, but to a lesser degree than normal oral feeding. Finally, the administration of CCK and gastrin, but not NT, restored the immune response against bacterial pneumonia. Enrichment of intravenous TPN with CCK, gastrin, and NT prevents GALT atrophy, especially in the distal bowel [93]. Of note, although each of these neuropeptides ameliorated the adverse effects of the lack of dietary stimulus in the lumen, only BBS completely inhibited such effects on 
Table 5. Role of GLN in the intestine and immune system

\begin{tabular}{|c|c|c|}
\hline Ref. & Experiment & Effect of GLN \\
\hline 87 & GLN supplementation in TPN mice & $\begin{array}{l}\text { Does not increase MAdCAM-1 expression in non-PP sites, which decreased } \\
\text { due to TPN }\end{array}$ \\
\hline 92 & GLN supplementation in TPN & Normalizes ICAM-1 expression caused by TPN administration \\
\hline 111 & $\begin{array}{l}\text { GLN-enriched early EN in rats after liver } \\
\text { transplantation }\end{array}$ & Protective effect on IMB injury \\
\hline 113 & GLN supplementation in TPN solutions & Maintains total intestinal tract cell mass, prevents intestinal mucosa atrophy \\
\hline 114 & $\begin{array}{l}\mathrm{GLN}+\mathrm{EN} \text {, before and after whole-body } \\
\text { radiotherapy }\end{array}$ & Decreases bacterial translocation and intestinal mucosal injury \\
\hline 116 & $\begin{array}{l}\text { In severely burned patients, EN+GLN, orally } \\
\text { for } 14 \text { days }\end{array}$ & $\begin{array}{l}\text { Decreases plasma diamine oxidase activity and urinary lactulose to mannitol } \\
\text { ratio, reduces the degree of intestine injury, and mucosal permeability, } \\
\text { accelerates wound healing and shortens hospital stay }\end{array}$ \\
\hline 117 & $\mathrm{EN}+\mathrm{GLN}$ vs. conventional EN in burned mice & $\begin{array}{l}\text { Improves intestinal immunity, increases total lymphocyte numbers and } \\
\text { intestinal IgA levels, decreases the total PP apoptotic ratio }\end{array}$ \\
\hline
\end{tabular}

Table 6. Role of ARG in the intestine and immune system

\begin{tabular}{lll}
\hline Ref. & Experiment & Effect of ARG \\
\hline 115 & ARG after gut ischemia/reperfusion & $\begin{array}{l}\text { Deactivates early proinflammatory transcription factors, NF- } \kappa \text { B, } \\
\text { and increases activator protein (AP-1) expression }\end{array}$ \\
\hline 119 & $\begin{array}{l}\text { ARG for } 3 \text { days before and after cecal ligation and } \\
\text { puncture (CLP) vs. intravenous ARG after CLP in rats } \\
\text { with septic peritonitis }\end{array}$ & $\begin{array}{l}\text { Improved intestinal immunity, enhanced systemic IL-10 } \\
\text { secretion vs. no favorable effects on mucosal immunity }\end{array}$ \\
\hline 120 & ARG supplementation in EN in severely burned mice & $\begin{array}{l}\text { Changes intestinal cytokine concentrations, homogenates from a } \\
\text { pro- to an anti-inflammatory profile, increases (i) secretory IgA } \\
\text { levels, (ii) lymphocyte numbers, and (iii) levels of IL-4 and IL-10, } \\
\text { decreases IFN- } \gamma \text { and IL-2 compared to EN-fed mice }\end{array}$ \\
\hline
\end{tabular}

GALT. In conclusion, exogenous administration of neuropeptides, such as CCK, gastrin, and NT, represents a promising choice against bacterial invasion in patients who cannot receive EN during critical illness or after GI removal [95]. The presumptive mechanism of NT action is that the pathogenic agent binds to receptors in the luminal surface of the enterocyte, leading to production of proinflammatory cytokines. These cytokines stimulate $\mathrm{N}$-cells to release NT, which in turn stimulates target cells (e.g. macrophages, mast cells, neutrophils, endothelial cells) [96]. The stimulation of NT target cells is thought to be achieved via two distinct pathways. The first is through NF- $\kappa \mathrm{B}$ activation, which is primarily involved in the inflammation process, while the second is through Ras proteins and is mainly involved in cell proliferation.

Miller et al. [97] succeeded in reversing the stimulatory effect of NT on mast cells, through the NT receptor antagonist, SR48692. Besides mast cells, NT also affects neutrophils, T cells and macrophages by promoting activation, phagocytosis and cytokine release. Moreover, ad- 
ministration of the NT antagonist, SR48692, reversed the inflammatory response through reduction of the neutrophil infiltration stabilization of the intestinal barrier inhibition of macrophage activation [97]. Table 4 highlights the roles of NT in the immune system [98-103].

\section{Glutamine-Arginine}

The addition of GLN to TPN solution significantly reduces the adverse effects of intestinal nutrition deprivation in the GALT. GLN is an important substrate for the cells of the intestinal mucosa, but it is not usually added to TPN solution, mainly due to the need for long-term stability of the solution. Replacing $2 \%$ of the protein load of the TPN solution with GLN improves the overall lymphocyte mass of the PP and the basic membrane and restores the ratio $\mathrm{CD} 4 / \mathrm{CD} 8$ in the basic membrane and the levels of IgA in the GI and in lungs [104, 105]. It also preserves IL- 4 but not IL-10 production from the gut [92, $105]$. Like BBS, GLN prevents some but not all the consequences of non-specific activation of neutrophil lymphocytes. Finally, GLN improves the survival of animals after visceral or gut ischemia-reperfusion but not to the degree that normal oral feeding does, whereas arginine (ARG) may deteriorate the function of the mucosal barrier and enhance permeability [106, 107]. GLN-enriched TPN preserved both extraintestinal and intestinal $\operatorname{IgA}$ levels and had a normalizing effect on Th2-type IgA-stimulating cytokines [105, 108-110]. TPN reduced intestinal and respiratory IgA along with decreases in intestinal IL-4 and IL-10 compared with chow-fed animals. GLN significantly improves respiratory and intestinal IgA levels, significantly improved IL-4 compared with TPN animals, and maintained IL-10 levels midway between chow-fed and TPN animals $[105,108-110]$. Table 5 summarizes evidence about the role of GLN to the intestine and immune system [111-117].

Minimal hypocaloric EN is recommended to avoid the overfeeding syndrome and gut hypoperfusion as well as early luminal delivery of pharmaconutrients (ARG, GLN dipeptides, antioxidants, butyrate) in conditions of splanchnic hypoperfusion. ARG may prevent intestinal injury due to hypoperfusion but may be harmful if ischemia is established. In contrast, GLN may be helpful in both conditions [118]. Intestinal ARG supplementation before sepsis tended to increase total lymphocyte numbers in PP and intestinal IgA secretion. Table 6 summarizes evidence about the role of ARG to the intestine and immune system $[119,120]$.

\section{Conclusions}

There are clear clinical differences between types of artificial nutrition depending on the route of administration and the composition of the solution. The full macromolecular solution of EN ensures an adequate mucous immune response, while lack of nutritional stimulus in the lumen rapidly leads to a dysfunction of GALT and mucosal immune system. This dysfunction renders the patients susceptible to distant organ infections, hospital pneumonia, and multiorgan failure of non-infectious etiology. Therefore, we should administer a complete macromolecular solution of intestinal nutrition orally or through a nasointestinal tube, gastrotomy or jejunostomy, to feed patients, unless there is an absolute contraindication. In patients with indication of TPN administration, addition of BBS or GLN preserves the mucosal immune response and may limit the adverse effects of TPN.

\section{References}

$>1$ Moore EE, Jones TN: Benefits of immediate jejunostomy feeding after major abdominal trauma - a prospective, randomized study. J Trauma 1986;26:874-881.

$\checkmark 2$ Moore FA, Moore EE, Jones TN, McCroskey BL, Peterson VM: TEN versus TPN following major abdominal trauma-reduced septic morbidity. J Trauma 1989;29:916-923.

$>3$ Kudsk KA, Croce MA, Fabian TC, Minard G, Tolley EA, Poret HA, Kuhl MR, Brown RO: Enteral versus parenteral feeding. Effects on septic morbidity after blunt and penetrating abdominal trauma. Ann Surg 1992;215:503511 .
4 Moore FA, Moore EE, Kudsk KA, Brown RO, Bower RH, Koruda MJ, Baker CO, Barbul A: Clinical benefits of an immune-enhancing diet for early postinjury enteral feeding. J Trauma 1994;37:607-615.

5 Mulholland MW, Lillemore KD, Doherty GM, Maier RV, Upchurch GR: Greenfield's Surgery Scientific Principles and Practice, ed 4: Anatomy and Physiology of Small Intestine. Philadelphia, Lippincott Williams \& Wilkins, 2005, chapt 49, pp 756-767.

$\checkmark 6$ Rowlands BJ, Soong CV, Gardiner KR: The gastrointestinal tract as a barrier in sepsis. $\mathrm{Br}$ Med Bull 1999;55:196-211.
7 Meyer N, Kudsk KA: Enteral versus parenteral nutrition: alteration in mechanisms of function in mucosal host defenses; in Cynober L, Moore FA (eds): Nutrition and Critical Care. Basel, Karger, 2003, pp 133-142.

$>8$ Duran B: The effects of long-term total parenteral nutrition on gut mucosal immunity in children with short bowel syndrome: a systematic review. BMC Nurs 2005;4:2.

-9 Sun X, Spencer AU, Yang H, Haxhija EQ, Teitelbaum DH: Impact of caloric intake on parenteral nutrition-associated intestinal morphology and mucosal barrier function. JPEN J Parenter Enteral Nutr 2006;30:474-479. 
$\checkmark 10$ Heel KA, Kong SE, McCauley RD, Erber WN, Hall JC: The effect of minimum luminal nutrition on mucosal cellularity and immunity of the gut. J Gastroenterol Hepatol 1998;13: 1015-1019.

-11 Ioannidis O, Lavrentieva A, Botsios D: Nutrition support in acute pancreatitis. JOP 2008; 9:375-390.

12 Kudsk KA, Minard G, Croce MA, Brown RO, Lowrey TS, Pritchard FE, Dickerson RN, Fabian TC: A randomized trial of isonitrogenous enteral diets after severe trauma. An immune-enhancing diet reduces septic compilations. Ann Surg 1996;224:531-540.

13 Goldberg RF, Austen WG Jr, Zhang X, Munene G, Mostafa G, Biswas S, McCormack M, Eberlin KR, Nguyen JT, Tatlidede HS, Warren HS, Narisawa S, Millán JL, Hodin RA: Intestinal alkaline phosphatase is a gut mucosal defense factor maintained by enteral nutrition. Proc Natl Acad Sci USA 2008; 105:35513556.

14 Lichtman SM: Bacterial translocation in humans. J Pediatr Gastroenterol Nutr 2001;33: $1-10$.

15 Balzan S, de Almeida Quadros C, de Cleva R, Zilberstein B, Cecconello I: Bacterial translocation: overview of mechanisms and clinical impact. J Gastroenterol Hepatol 2007;22:464-471.

16 Steinberg SM: Bacterial translocation: what it is and what it is not. Am J Surg 2003;186:301305.

17 Deitch EA: Multiple organ failure. Pathophysiology and potential future therapy. Ann Surg 1992;216:117-134.

18 Deitch EA: Bacterial translocation of the gut flora. J Trauma 1990;30(suppl):S184-S189.

19 Deitch EA: Intestinal permeability is increased in burn patients shortly after injury. Surgery 1990;107:411-416.

20 Langkamp-Henken B, Donovan TB, Pate LM, Maull CD, Kudsk KA: Increased intestinal permeability following blunt and penetrating trauma. Crit Care Med 1995;23:660-664.

21 Harris CE, Griffiths RD, Freestone N, Billington D, Atherton ST, Macmillan RR: Intestinal permeability in the critically ill. Intensive Care Med 1992;18:38-41.

22 Kanwar S, Windsor AC, Welsh F, Barclay GR, Guillou PJ, Reynolds JV: Lack of correlation between failure of gut barrier function and septic complications after major upper gastrointestinal surgery. Ann Surg 2000;231:88-95.

-23 Ohta K, Omura K, Hirano K, Kanehira E, Ishikawa N, Kato Y, Kawakami K, Watanabe G: The effects of an additive small amount of a low residual diet against total parenteral nutrition-induced gut mucosal barrier. Am J Surg 2003;185:79-85.

-24 Dervenis C, Smailis D, Hatzitheoklitos E: Bacterial translocation and its prevention in acute pancreatitis. J Hepatobiliary Pancreat Surg 2003; 10:415-418.

-25 Hsu CM, Liu CH, Chen LW: Nitric oxide synthase inhibitor ameliorates oral total parenteral nutrition-induced barrier dysfunction. Shock 2000;13:135-139.
26 Deitch EA, Sittig K, Li M, Berg R, Specian RD: Obstructive jaundice promotes bacterial translocation from the gut. Am J Surg 1990; 159:79-84.

-27 Assimakopoulos SF, Scopa CD, Vagianos CE: Pathophysiology of increased intestinal permeability in obstructive jaundice. World J Gastroenterol 2007;13:6458-6464.

28 Assimakopoulos SF, Vagianos CE, Charonis A, Nikolopoulou VN, Scopa CD: Intestinal failure in obstructive jaundice. World J Gastroenterol 2005;11:3806-3807

29 Peng JS, Zhao XL, Zhan WH, Zhao ZG, Yin Y: Effect of ecoimmunonutrition on gut barrier function in rats with systemic inflammatory response syndrome (in Chinese). Zhonghua Wei Chang Wai Ke Za Zhi 2005;8:162-164.

-30 Zhang MM, Cheng JQ, Zhai HJ, Lu YR, Chen YN, Wu XT: Influence of ecoimmunonutrition supplement on intestinal mucosa morphology and gut barrier function in rats after operative stress (in Chinese). Zhonghua Wei Chang Wai Ke Za Zhi 2009;12:306-309.

31 Xu GF, Lu Z, Gao J, Li ZS, Gong YF: Effect of ecoimmunonutrition supports on maintenance of integrity of intestinal mucosal barrier in severe acute pancreatitis in dogs. Chin Med J (Engl) 2006;119:656-661.

32 Moore FA, Moore EE, Poggetti R, McAnena OJ, Peterson VM, Abernathy CM, Parsons PE: Gut bacterial translocation via the portal vein: a clinical perspective with major torso trauma. J Trauma 1991;31:629-636.

-33 Deitch EA: Bacterial translocation or lymphatic drainage of toxic products from the gut: what is important in human beings? Surgery 2002;131:241-244.

- 34 Adams CA Jr, Xu DZ, Lu Q, Deitch EA: Factors larger than $100 \mathrm{kDa}$ in post-hemorrhagic shock mesenteric lymph are toxic for endothelial cells. Surgery 2001;129:351-363.

35 Lemaire LC, van Lanschot JB, Stoutenbeek CP, van Deventer SJ, Dankert J, Oosting H, Gouma DJ: Thoracic duct in patients with multiple organ failure: no major route of bacterial translocation. Ann Surg 1999;229:128136.

36 Peng YZ, Yuan ZQ, Xiao GX: Effects of early enteral feeding on the prevention of enterogenic infection in severely burned patients. Burns 2001;27:145-149.

37 Lehocky P, Sarr MG: Early enteral feeding in severe acute pancreatitis: can it prevent secondary pancreatic (super) infection? Dig Surg 2000;17:571-577.

38 Kang W, Kudsk KA: Is there evidence that the gut contributes to mucosal immunity in humans? JPEN J Parenter Enteral Nutr 2007;31: 246-258.

39 DeWitt RC, Kudsk KA: The gut's role in metabolism, mucosal barrier function, and gut immunology. Infect Dis Clin North Am 1999; 13:465-481, x.
40 Ikezawa F, Fukatsu K, Moriya T, Ueno C, Maeshima Y, Okamoto K, Hara E, Saitoh D: Reversal of parenteral nutrition-induced gut mucosal immunity impairment with small amounts of a complex enteral diet. J Trauma 2008;65:360-366.

41 Schmidt H, Martindale R: The gastrointestinal tract in critical illness. Curr Opin Clin Nutr Metab Care 2001;4:547-551.

42 Kang W, Kudsk KA, Sano Y, Lan J, Yang-Xin F, Gomez FE, Maeshima Y: Effects of lymphotoxin $\beta$-receptor blockade on intestinal mucosal immunity. JPEN J Parenter Enteral Nutr 2007;31:358-365.

43 Kang W, Gomez FE, Lan J, Sano Y, Ueno C, Kudsk KA: Parenteral nutrition impairs gutassociated lymphoid tissue and mucosal immunity by reducing lymphotoxin $\beta$-receptor expression. Ann Surg 2006;244:392-399.

44 Brandtzaeg P: The role of J chain and secretory component in receptor-mediated glandular and hepatic transport of immunoglobulins in man. Semin Respir Infect 1985;22:111.

45 Wu Y, Kudsk KA, DeWitt RC, Tolley EA, Li $\mathrm{J}$ : Route and type of nutrition influence IgAmediating intestinal cytokines. Ann Surg 1999;229:662-668.

46 Johnson CD, Kudsk KA, Fukatsu K, Renegar $\mathrm{KB}$, Zarzaur BL: Route of nutrition influences generation of antibody-forming cells and initial defense to an active viral infection in the upper respiratory tract. Ann Surg 2003;237:565-573.

-47 Fukatsu K, Moriya T, Murakoshi S, Yasuhara $\mathrm{H}$ : Interleukin-7 treatment reverses parenteral nutrition-induced impairment of resistance to bacterial pneumonia with increased secretory immunoglobulin A levels. J Surg Res 2012;174:334-338.

48 Fukatsu K, Moriya T, Ikezawa F, Maeshima Y, Omata J, Yaguchi Y, Okamoto K, Mochizuki $\mathrm{H}$, Hiraide $\mathrm{H}$, Hardy G: Interleukin-7 dosedependently restores parenteral nutrition-induced gut-associated lymphoid tissue cell loss but does not improve intestinal immunoglobulin A levels. JPEN J Parenter Enteral Nutr 2006;30:388-394.

49 Sano Y, Gomez FE, Hermsen JL, Kang W, Lan J, Maeshima Y, Kudsk KA: Parenteral nutrition induces organ-specific alterations in polymeric immunoglobulin receptor levels. J Surg Res 2008;149:236-242.

50 Li J, Kudsk KA, Gocinski B, Dent D, Glezer J, Langkamp-Henken B: Effects of parenteral and enteral nutrition on gut-associated lymphoid tissue J. Trauma 1995;39:44-52.

51 Gomez FE, Lan J, Kang W, Ueno C, Kudsk KA: Parenteral nutrition and fasting reduces mucosal addressin cellular adhesion molecule-1 mRNA in Peyer's patches of mice. JPEN J Parenter Enteral Nutr 2007;31:47-52.

52 Fukatsu K, Zarzaur BL, Johnson CD, Wu Y, Wilcox HG, Kudsk KA: Decreased MAdCAM-1 expression in Peyer's patches: a mechanism for impaired mucosal immunity during lack of enteral nutrition. Surg Forum 2000;51:211-214. 
53 Lebman DA, Coffman RL: Cytokines in the mucosal immune system; in Ogra PL, Lamm ME, McGhee JR, Mestecky J, Strober W, Bienenstock J (eds): Handbook of Mucosal Immunology. San Diego, Academic Press, 1994, pp 243-249.

54 Hermsen JL, Gomez FE, Maeshima Y, Sano Y, Kang W, Kudsk KA: Decreased enteral stimulation alters mucosal immune chemokines. JPEN J Parenter Enteral Nutr 2008;32:36-44.

55 Genton L, Kudsk KA, Reese SR, Ikeda S: Enteral feeding preserves gut Th- 2 cytokines despite mucosal cellular adhesion molecule-1 blockade. JPEN J Parenter Enteral Nutr 2005; 29:44-47.

56 Ikeda S, Kudsk KA, Fukatsu K, Johnson CD, Le T, Reese S, Zarzaur BL: Enteral feeding preserves mucosal immunity despite in vivo MAdCAM-1 blockade of lymphocyte homing. Ann Surg 2003;237:677-685.

57 Renegar KB, Kudsk KA, Dewitt RC, Wu Y, King BK: Impairment of mucosal immunity by parenteral nutrition: depressed nasotracheal influenza-specific secretory IgA levels and transport in parenterally fed mice. Ann Surg 2001;233:134-138.

-58 Phillips JO, Everson MP, Moldoveanu Z, Lue C, Mestecky J: Synergistic effect of IL-4 and IFN- $\gamma$ on the expression of polymeric Ig receptor (secretory component) and IgA binding by human epithelial cells. J Immunol 1990;145:1740-1744.

-59 King BK, Kudsk KA, Li J, Wu Y, Renegar KB: Route and type of nutrition influence mucosal immunity to bacterial pneumonia. Ann Surg 1999;229:272-278.

60 Kudsk KA, Li J, Renegar KB: Loss of upper respiratory tract immunity with parenteral feeding. Ann Surg 1996;223:629-635.

-61 Lin MT, Saito H, Fukushima R: Route of nutritional supply influences local, systemic, and remote organ responses to intraperitoneal bacterial challenge. Ann Surg 1996;223:8493.

62 Ikeda S, Kudsk KA, Tho L, Zarzaur BL, Johnson CD: Glutamine improves impaired cellular exudation and polymorphonuclear neutrophil phagocytosis induced by TPN following glycogen-induced murine peritonitis. Shock 2002;18:119-124.

63 Moore EE, Moore FA, Franciose RJ, Kim FJ, Biffl WL, Banerjee A: The post-ischemic gut serves as a priming bed for circulating neutrophils that provoke multiple organ failure. J Trauma 1994;37:881-887.

- 64 Carlos T, Harian J: Leukocyte-endothelial adhesion molecules. Blood 1994;84:20682101.

-65 Fukatsu K, Kudsk KA, Zarzaur BL, Wu Y, Hanna MK, DeWitt RC: TPN decreases IL-4 and IL-10 mRNA expression in lipopolysaccharide-stimulated intestinal lamina propria cells but glutamine supplementation preserves the expression. Shock 2001;15:318322.
66 Fukatsu K, Lundberg AH, Hanna MK, Wu Y, Wilcox HG, Granger DN, Gaber AO, Kudsk KA: Increased expression of intestinal P-selectin and pulmonary E-selectin during intravenous total parenteral nutrition. Arch Surg 2000;135:1177-1182.

67 Fukatsu K, Lundberg AH, Hanna MK, Wu Y, Wilcox HG, Granger DN, Gaber AO, Kudsk KA: Route of nutrition influences intercellular adhesion molecule- 1 expression and neutrophil accumulation in intestine. Arch Surg 1999;134:1055-1060.

68 Kudsk KA: Current aspects of mucosal immunology and its influence by nutrition. Am J Surg 2002;183:390-398.

69 Guzy C, Schirbel A, Paclik D, Wiedenmann B, Dignass A, Sturm A: Enteral and parenteral nutrition distinctively modulate intestinal permeability and T-cell function in vitro. Eur J Nutr 2009;48:12-21.

70 Meyer NA, Kudsk KA: Enteral versus parenteral nutrition: alterations in mechanisms of function in mucosal host defenses. Nestle Nutr Workshop Ser Clin Perform Programme 2003;8:133-148.

71 Widlicka A: Enteral nutrition in the cardiothoracic intensive care unit: challenges and considerations. Nutr Clin Pract 2008;23:510-520.

72 Milo LA, Reardon KA, Tappenden KA: Effects of short-chain fatty acid-supplemented total parenteral nutrition on intestinal proinflammatory cytokine abundance. Dig Dis Sci 2002;47:2049-2055.

73 Ioannidis O, Varnalidis I, Paraskevas G, Mpotsios D: Nutritional modulation of inflammatory bowel response. Digestion 2011; 84:89-101.

74 Kudsk KA, Gomez FE, Kang W, Ueno C: Enteral feeding of a chemically defined diet preserves pulmonary immunity but not intestinal immunity: the role of lymphotoxin $\beta$-receptor. JPEN J Parenter Enteral Nutr 2007;31:477-481

75 Sigalet DL, Mackenzie SL, Hameed SM: Enteral nutrition and mucosal immunity: implications for feeding strategies in surgery and trauma. Can J Surg 2004;47:109-116.

76 Bengmark S: Synbiotics and the mucosal barrier in critically ill patients. Curr Opin Gastroenterol 2005;21:712-716.

77 Wang X, Pan L, Lu J, Li N, Li J: n-3 PUFAs attenuate ischemia/reperfusion induced intestinal barrier injury by activating I-FABPPPAR $\gamma$ pathway. Clin Nutr 2012;31:951-957.

-78 Rhoden D, Matheson PJ, Carricato ND, Spain DA, Garrison RN: Immune-enhancing enteral diet selectively augments ileal blood flow in the rat. J Surg Res 2002;106:25-30.

9 Fukatsu K, Kudsk KA, Zarzaur BL, Sabek O, Wilcox HG, Johnson CD: Increased ICAM-1 and $\beta_{2}$-integrin expression in parenterally fed mice after a gut ischemic insult. Shock 2002; 18:119-124.
80 Zonta S, Doni M, Alessiani M, Lovisetto F, Vigano J, Mazzilli M, Dominioni T, Podetta $\mathrm{M}$, De Martino M, Scaglione M, Vicini E, Bottazzi A, Villa C, Morbini P, Dionigi P: Elemental enteral nutrition preserves the mucosal barrier and improves the trophism of the villi after small bowel transplantation in piglets. Transplant Proc 2007;39:2024-2027.

81 Azuma H, Mishima S, Oda J, Homma H, Sasaki H, Hisamura M, Ohta S, Yukioka T: Enteral supplementation enriched with glutamine, fiber, and oligosaccharide prevents gut translocation in a bacterial overgrowth model. J Trauma 2009;66:110-114.

82 Murakoshi S, Fukatsu K, Omata J, Moriya T, Noguchi M, Saitoh D, Koyama I: Effects of adding butyric acid to $\mathrm{PN}$ on gut-associated lymphoid tissue and mucosal immunoglobulin A levels. JPEN J Parenter Enteral Nutr 2011;35:465-472.

83 Varnalidis I, Ioannidis O, Karamanavi E, Ampas Z, Poutahidis T, Taitzoglou I, Paraskevas G, Botsios D: Omega-3 fatty acids supplementation has an ameliorative effect in experimental ulcerative colitis despite increased colonic neutrophil infiltration. Rev Esp Enferm Dig 2011;103:511-518.

84 Debas HT, Mulvihill SJ: Neuroendocrine design of the gut. Am J Surg 1991;61:243-249.

85 Li J, Kudsk KA, Hamidian M, Gocinski BL: BBS affects mucosal immunity and gut-associated lymphoid tissue in intravenously fed mice. Arch Surg 1995;130:1164-1169.

86 Fujimura Y, Haruma K, Owen RL: BBS prevents the atrophy of Peyer's patches and the dysfunction of $\mathrm{M}$ cells in rabbits receiving long-term parenteral nutrition. JPEN J Parenter Enteral Nutr 2007;31:75-85.

- 87 Zarzaur BL, Ikeda S, Johnson CD, Le T, Sacks G, Kudsk KA: Mucosal immunity preservation with BBS or glutamine is not dependent on mucosal addressin cell adhesion molecule-1 expression. JPEN J Parenter Enteral Nutr 2002;26:265-270.

88 Zarzaur BL, Wu Y, Fukatsu K, Johnson CD, Kudsk KA: The neuropeptide BBS improves IgA-mediated mucosal immunity with preservation of gut interleukin- 4 in total parenteral nutrition-fed mice. Surgery 2002;131:59-65.

89 Sacks GS, Kudsk KA: Maintaining mucosal immunity during parenteral feeding with surrogates to enteral nutrition. Nutr Clin Pract 2003; 18:483-488.

90 Janu PG, Kudsk KA, Li J, Renegar KB: Effect of BBS on impairment of upper respiratory tract immunity induced by total parenteral nutrition. Arch Surg 1997;132:89-93.

91 DeWitt RC, Wu Y, Renegar KB, King BK, Li J, Kudsk KA: BBS recovers gut-associated lymphoid tissue and preserves immunity to bacterial pneumonia in mice receiving total parenteral nutrition. Ann Surg 2000;231:1-8.

92 Fukatsu K, Lundberg AH, Kudsk KA, Hanna MK, Johnson CD, Wu Y, Wilcox HG, Zarzaur BL: Modulation of organ ICAM-1 expression during IV-TPN with glutamine and BBS. Shock 2001;15:24-28. 
$\checkmark 93$ Keith Hanna M, Zarzaur BL Jr, Fukatsu K, Chance DeWitt R, Renegar KB, Sherrell C, Wu Y, Kudsk KA: Individual neuropeptides regulate gut-associated lymphoid tissue integrity, intestinal immunoglobulin A levels, and respiratory antibacterial immunity. JPEN J Parenter Enteral Nutr 2000;24:261269.

94 Zhao D, Pothoulakis C: Effects of NT on gastrointestinal motility and secretion, and role in intestinal inflammation. Peptides 2006; 27:2434-2444

95 Genton L, Kudsk KA: Interactions between the enteric nervous system and the immune system: role of neuropeptides and nutrition. Am J Surg 2003;186:253-258.

$\$ 6$ Fasano A, Nataro JP: Intestinal epithelial tight junctions as targets for enteric bacteriaderived toxins. Adv Drug Deliv Rev 2004;56: 795-807.

$\$ 97$ Miller LA, Cochrane DE, Carraway RE, Feldberg RS: Blockade of mast cell histamine secretion in response to neurotensin by SR48692, a nonpeptide antagonist of the neurotensin brain receptor. Br J Pharmacol 1995;114:1466-1470.

98 Evers BM: Neurotensin and growth of normal and neoplastic tissues. Peptides 2006;27: 2424-2433.

99 Vagianos C, Karatzas T, Scopa CD, Panagopoulos C, Tsoni I, Spiliopoulou I, Kalfarentzos F: Neurotensin reduces microbial translocation and improves intestinal mucosa integrity after abdominal radiation. Eur Surg Res 1992;24:77-83.

100 Lazarus LH, Perrin MH, Brown MR, Rivier JE: Mast cell binding of neurotensin. II. Molecular conformation of neurotensin involved in the stereospecific binding to mast cell receptor sites. J Biol Chem 1977;252: 7180-7183.

101 Castagliuolo I, Wang CC, Valenick L, Pasha A, Nikulasson S, Carraway RE, Pothoulakis C: Neurotensin is a proinflammatory neuropeptide in colonic inflammation. J Clin Invest 1999;103:843-849.
02 Assimakopoulos SF, Alexandris IH, Scopa CD, Mylonas PG, Thomopoulos KC, Georgiou CD, Nikolopoulou VN, Vagianos CE: Effect of BBS and neurotensin on gut barrier function in partially hepatectomized rats. World J Gastroenterol 2005;11:6757-6764.

103 Renegar KB, Johnson CD, Dewitt RC, King BK, Li J, Fukatsu K, Kudsk KA: Impairment of mucosal immunity by total parenteral nutrition: requirement for IgA in murine nasotracheal anti-influenza immunity. J Immunol 2001;166:819-825.

104 Li J, Kudsk KA, Janu P, Renegar KB: Effect of glutamine-enriched total parenteral nutrition on small intestinal gut-associated lymphoid tissue and upper respiratory track immunity. Surgery 1997;121:542-549.

105 Kudsk KA, Wu Y, Fukatsu K, Zarzaur BL, Johnson CD, Wang R, Hanna MK: Glutamine-enriched total parenteral nutrition maintains intestinal interleukin-4 and mucosal immunoglobulin A levels. JPEN J Parenter Enteral Nutr 2000;24:270-274.

106 Aguilar-Nascimento JE: The role of macronutrients in gastrointestinal blood flow. Curr Opin Clin Nutr Metab Care 2005;8: 552-556.

107 Ikeda S, Zarzaur BL, Johnson CD, Fukatsu $\mathrm{K}$, Kudsk KA: Total parenteral nutrition supplementation with glutamine improves survival after gut ischemia/reperfusion. JPEN J Parenter Enteral Nutr 2002;26:169173.

108 Burke DJ, Alverdy JC, Aoys E, Moss GS: Glutamine-supplemented total parenteral nutrition improves gut immune function. Arch Surg 1989;124:1396-1399.

109 DeWitt RC, Wu Y, Renegar KB, Kudsk KA: Glutamine-enriched total parenteral nutrition preserves respiratory immunity and improves survival to a Pseudomonas pneumonia. J Surg Res 1999;84:13-18.

110 Lai YN, Yeh SL, Lin MT, Shang HF, Yeh CL, Chen WJ: Glutamine supplementation enhances mucosal immunity in rats with gutderived sepsis. Nutrition 2004;20:286-291.

-111 Li Y, Chen Y, Zhang J, Zhu JF, Liu ZJ, Liang SY, Sun K, Liao WY, Gong JP: Protective effect of glutamine-enriched early enteral nutrition on intestinal mucosal barrier injury after liver transplantation in rats. Am J Surg 2010;199:35-42.
112 Kudsk KA: Effect of route and type of nutrition on intestine-derived inflammatory responses. Am J Surg 2003;185:16-21.

113 O’Dwyer ST, Smith RJ, Hwang TL, Wilmore DW: Maintenance of small bowel mucosa with glutamine- enriched parenteral nutrition. JPEN J Parenter Enteral Nutr 1989;13 579-585.

114 Salman B, Oguz M, Akmansu M, Bebitoglu I, Akca G, Sultan N, Emre U, Kerem M, Yilmaz U: Effect of timing of glutamine-enriched enteral nutrition on intestinal damage caused by irradiation. Adv Ther 2007;24: 648-661.

115 Sato N, Moore FA, Smith MA, Zou L, Moore-Olufemi S, Schultz SG, Kozar RA Immune-enhancing enteral nutrients differentially modulate the early proinflammatory transcription factors mediating gut ischemia/reperfusion. J Trauma 2005;58:455461.

116 Peng X, Yan H, You Z, Wang P, Wang S: Effects of enteral supplementation with glutamine granules on intestinal mucosal barrier function in severe burned patients. Burns 2004;30:135-139.

117 Fan J, Meng Q, Guo G, Xie Y, Xiu Y, Li T, Feng W, Ma L: Effects of enteral nutrition supplemented with glutamine on intestinal mucosal immunity in burned mice. Nutrition 2009;25:233-239.

118 Aguilar-Nascimento JE, Dock-Nascimento $\mathrm{DB}$, Bragagnolo R: Role of enteral nutrition and pharmaconutrients in conditions of splanchnic hypoperfusion. Nutrition 2010; 26:354-358

119 Shang HF, Wang YY, Lai YN, Chiu WC, Yeh SL: Effects of arginine supplementation on mucosal immunity in rats with septic peritonitis. Clin Nutr 2004;23:561-569.

120 Fan J, Meng Q, Guo G, Xie Y, Li X, Xiu Y, Li T, Ma L: Effects of early enteral nutrition supplemented with arginine on intestinal mucosal immunity in severely burned mice. Clin Nutr 2010;29:124-130. 